\title{
Triple A Sendromlu Bir Olgu Sunumu
}

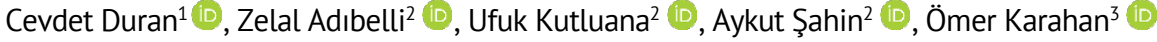 \\ 1 Endokrinoloji ve Metabolizma Hastalıkları Bilim Dalı, İç Hastalıkları Anabilim Dalı, Uşak Üniversitesi, Tıp Fakültesi, Uşak/Türkiye \\ 2 İç Hastalıkları Anabilim Dalı, Uşak Üniversitesi, Tıp Fakültesi, Uşak/Türkiye \\ 3 Genel Cerrahi Anabilim Dalı, Uşak Üniversitesi, Tıp Fakültesi, Uşak/Türkiye
}

\section{$\ddot{O Z E T}$}

Triple A veya Allgrove sendromu, kalıtsal geçişli bir sendrom olup, başlıca akalazya, alakrima ve adrenokortikotropin (ACTH) direnci-addisoniyanizm ile karakterizedir. Bu yazımızda başlangıçta Addison hastalığı tanısı konulan, ancak takiplerinde ACTH direnci-addisoniyanizmi ve akalazyası saptanan, akalazya için önce buji dilatasyonu, devamında Heller's miyotomi yapılan, ayrıca yine takiplerinde alakrima ve vokal kord paralizisi gelişen Triple A sendromlu, 48 yaşındaki bir erkek bir olguyu sunduk. Triple $A$ sendromunda ACTH direncine bağlı adrenal yetersizlik gelişmekte ve hastalığın diğer komponentleri başlangıçta ortaya çıkmayabilmektedir. Ayrıca bazı olgularda nörolojik bozukluklarda görülebilmektedir. Özellikle mineralokortikoid ihtiyacı olmayan adrenal yetersizliği olan olgular addisoniyanizm ve sendromun diğer spesifik iki bulgusu olan akalazya ve alakrima gelişimi yönünden takip edilmelidir.

Anahtar Kelimeler: Triple A sendromu, Allgrove sendromu, addisoniyanizm, akalazya, alakrima

\section{ABSTRACT}

Triple A or Allgrove syndrome is a hereditary syndrome primarily characterized by achalasia, alacrima and adrenocorticotropin (ACTH) resistance-addisonianism. In this report, we presented a 48-year-old man with Triple $A$ syndrome that had been initially diagnosed with Addison's disease, then determined with ACTH resistance-addisonianism and achalasia during the follow-ups, for whom first bougie dilatation and then Heller's myotomy were performed due to the achalasia, and alacrima and vocal cord paralysis also developed in the follow-ups. In Triple A syndrome, adrenal insufficiency due to ACTH resistance is to develop, and other components of the disease may not be develop at initial. In addition, neurological disorders may also be observed in some cases. The cases with adrenal insufficiency, especially those who do not need mineralocorticoids, should be followed for the development of achalasia and alacrima, two other specific components of Allgrove syndrome.

Keywords: Triple A syndrome, Allgrove syndrome, addisonianism, achalasia, alacrima

\section{GíRiş}

Triple A, diğer adıyla Allgrove sendromu, kalıtsal geçişli bir sendrom olup, başlıca akalazya, alakrima ve adrenokortikotropin (ACTH) direnci-addisoniyanizm ile karekterizedir (1-5). Akalazya ya bağlı yutma ve beslenme problemleri, addisoniyanizme bağı yorgunluk, iştah kaybı, hipotansiyon ve ciltte koyulaşma, alakrimaya bağıı gözlerde yanma, batma, kuru göz görülebilir (3). Bazı olgularda nörolojik belirtilerde eşlik etmektedir (6-8). Olguların çoğunda bu üç majör özellik birlikte olsa da bazı olgularda iki özellik beraberdir (9). Bu yazımızda uzun yıllar Addison hastalığı tanısıyla takip olan ve devamında Triple A sendromu tanısı alan; akalazya, addisoniyanizm, alakrima ve bazı nörolojik belirtileri olan bir erkek olgu sunduk.

\section{OLGU}

48 yaşında, erkek, son zamanlarda olan öksürük ve balgam yakınması ile başvurdu. Hikayesinde yaklaşık 30 yıl önce, askerlik görevi esnasında iştahsızlık, halsizlik, kilo kaybı, dermansızlık, renkte koyulaşma olması nedeniyle başka bir merkezde hastaneye yatırılmış ve hastaya Addison hastalığı tanısı konularak oral steroid tedavisi (Prednizolon 7.5 mg/gün, bölünmüş dozlarda) başlanmış. Takiplerinde şikayetlerinin büyük kısmı gerilemiş, ancak devam eden süreçte yutma problemleri ve konuşma problemleri başlamış. Yutma problemi katı ve sıvı gıdalara karşı benzer şekildeymiş. Daha önceden bakılan plazma ACTH düzeyleri $785 \mathrm{pg} / \mathrm{mL}$ ve $317 \mathrm{pg} / \mathrm{mL}$ ( $\mathrm{N}=0-46 \mathrm{pg} / \mathrm{mL}$ ) bulunmuş ve serum potasyum düzeyleri normal sınırlarda imiş. Addison hastalığı tanısı olmasına rağmen mineralokortikoid ihtiyacı

Yazışma Adresi/Address for Correspondence: Cevdet Duran, MD, Uşak Üniversitesi, Tıp Fakültesi, İç Hastalıkları Anabilim Dalı, Endokrinoloji ve Metabolizma Hastalıkları Bilim Dalı, Uşak/Türkiye

E-Posta/E-Mail: drcduran@gmail.com || Tel: +905334298585

Received/Geliş Tarihi: 03.02.2019 || Accepted/Kabul Tarihi: 17.02.2019

Bu Eser Creative Commons Atıf-Gayriticari 4.0 Uluslararası Lisansı İle Lisanslanmıştır. This work is licensed under a Creative Commons

Attribution-NonCommercial 4.0 International License (CC BY-NC 4.0). 
olmayan hastada, yutma problemi de olması nedeniyle tarafımızca daha önceden Triple A sendromu tanısı konulmuş. Hastaya tarafımızca hidrokortizon $3 \times 10 \mathrm{mg}$ başlanmış, disfajisi olduğu için baryum özofagus grafisi çekilmiş ve görüntü akalazya için tipik olmamakla beraber, özofagokardiya bileşkesinde kontrastın künt sonlanım gösterdiği ve özofagus alt ucunda darlık olduğu saptanmış (Resim 1), bunun üzerine kitle ekartasyonu amaçlı üst gastrointestinal sistem (GIS) endoskopisi yapılmış ve kesici dişlerden itibaren yaklaşık 38-40. cm civarında Z çizgisi üzerinde darlık olduğu ve bunun öncesinde özofagusta genişlik olduğu saptanmış, görünümün öncelikle akalazya ile uyumlu düşünülerek Nifedipin 1-3×30 mg dozunda başlanmıştı. Bu tedavi ile başlangıçta disfaji yakınmasında gerileme olmasına rağmen devam eden süreçte disfaji ilerlemiş ve odinofaji yakınması eklenmiş. Bunun üzerine hastaya tarafımızca buji dilatasyonu yapılmış, dilatasyondan başlangıçta kısmen fayda görmüş, ancak devam eden süreçte yeniden yakınmaları başlaması üzerine 2018 yılında dış merkezde Heller's myotomi operasyonu yapılmış, cerrahi sonrası yutma yakınması büyük oranda gerilemişti. Daha önceden kuru göz yakınması olmayan hastanın son aylarda gözlerde batma yakınması başlamış. Son zamanlarda da öksürük ve pürülan karakterde balgam yakınması olan hasta yeniden hastaneye yatırıldı.

Resim 1. Olgunun baryumlu özofagus grafisi. Baryumlu özofagus grafisi akalazya için tipik olmamakla beraber, özofagus içindeki baryumlu kontrast özofagokardiyak bileşkede künt olarak sonlanmakta, bu düzeyde darlık (kitleye bağlı görünüm?) ve darlık sonrası mide ile uyumlu mukozal kontrast sıvanması izlenmekte. Darlık öncesi özofagusda dilatasyon ve tersiyer kontraksiyonlar izlenmektedir.

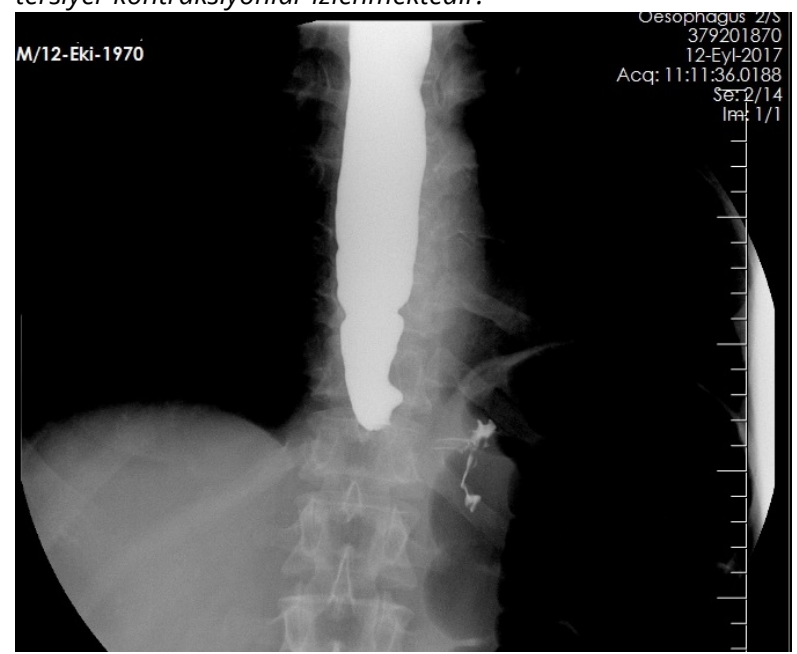

Öz ve soy geçmişinde özellik yoktu, sigara, alkol veya herhangi bir bağımlııı yapacak ilaç-madde kullanmıyordu.

Fizik muayenede; kaşektik görünümde, cilt hafif koyu, 165 cm, 50 kg, BMI 18.3 kg/m2, kan basıncı 100/50 mmHg idi ve ortostatik değişiklik yoktu. Konuşma dizartrik ve nazone idi. Kas gücü alt ekstremitelerde $4 / 5$ olarak saptandı. Diğer sistem muayenelerinde özellik yoktu.

Biyokimyasal incelemede kan şekeri $80 \mathrm{mg} / \mathrm{dL}$ ( $\mathrm{N}=70-105$ $\mathrm{mg} / \mathrm{dL})$, kreatinin $1.05 \mathrm{mg} / \mathrm{dL} \quad(\mathrm{N}=0.7-1.3 \mathrm{mg} / \mathrm{dL})$, sodyum $144 \mathrm{mmol} / \mathrm{L}(\mathrm{N}=136-146 \mathrm{mmol} / \mathrm{L})$, potasyum $4 \mathrm{mmol} / \mathrm{L}$ $(\mathrm{N}=3.5-5.1 \mathrm{mmol} / \mathrm{L})$, plazma $\mathrm{ACTH}$ düzeyleri ise 14.4 ile 62.9 $\mathrm{pg} / \mathrm{mL}(\mathrm{N}=0.46 \mathrm{pg} / \mathrm{mL})$ arasında saptandı.

Hastanın öksürük ve balgam yakınması nedeniyle göğüs hastalıkları ve kulak burun boğaz tarafından değerlendirildi. Erdostein ve nazal steroidli spray verildi ve yakınmaları geriledi. Sağ vokal kord paralizisi saptandı ve çekilen larinks BT normal saptandı. Kontrol üst GIS endoskopide kronik superfisial gastrit ve akalazya ile uyumlu olarak değerlendirildi, proton pompa inhibitörü tedavisi başlandı. Nörolojik yakınmalar için beyin difüzyon MR çekildi, mikroiskemik alanlar saptandı ve klopidogrel 75 mg başlandı. Kuru göz açısından göz hastalıkları tarafından değerlendirilen hastada Schirmer's testi $5 \mathrm{dk}$. da $5 \mathrm{~mm}$ den küçük ölçüldü ve kuru göz olarak değerlendirildi, suni göz yaşı damlası ve konjuktivit için deksametazon ve tobramisinli damla verildi. Yakınmaları gerileyen hasta poliklinik kontrollerine gelmek üzere taburcu edildi.

\section{SONUÇ}

Triple A sendromu, diğer adlarılla AAA sendromu veya Allgrove sendromu, sıklığı tam olarak bilinmeyen, akalazya, ACTH direnci-addisoniyanizm ve alakrima ile seyreden, bazı olgularda nörolojik belirti ve bulgularında eşlik ettiği, otozomal resesif geçişli kalıtımsal bir hastalıktır (1-5). Olguların çoğunda üç komponent olsa da bazı olgularda başlıca iki komponent görülebilir (9).

İşlevi tam anlaşılmamış olan ALADIN adlı proteini kodlayan AAAS genindeki mutasyon bu sendroma sebep olur (10-12). ALADIN nükleer zarfta bulunur ve onu hücrenin geri kalan kısmından ayırır. ALADIN eksikliğinde nükleer tamir proteinlerinin çekirdeğe giremeyeceği ve hasara neden olacağı, onarılmayan DNA'nın da hücrenin dengesi hale gelmesine ve ölümüne sebep olacağı iddia edilmiştir. 
ACTH direncine bağlı adrenal yetersizlik triple A sendromunun önemli özelliklerindendir $(1,13)$. Primer adrenokortikal yetersizlik olguların \%1'inden azında sebep triple A sendromudur (14). ACTH direnci ve buna bağlı kortizol eksikliğine bağı yorgunluk, iştah kaybı, kilo kaybı, kan basıncı düşüklüğü ve ciltte koyulaşma olabilir. Hem adrenal yetersizlik hem de akalazya ya bağlı beslenme kusurları bu hastalardaki kilo kaybının önemli etmenidir. Triple A sendromlu hastalarda genelde ACTH direnci olduğu için mineralokortikoid salınımı korunmuştur ve bu nedenle de mineralokortikoid intiyacı olmaz. Özellikle mineralokortikoid ihtiyacı olmayan addison hastaları triple A sendromu gelişimi açısından takip edilmelidirler. Triple A sendromlu hastalar mutlaka steroid tedavisine devam etmeli, ayrıca adrenal yetersizlik açısından bilgilendirilmeli ve gerektiğinde yüksek doz steroid replasmanı yapılmalıdır. Akalazya; özofagus peristalizm yokluğu ve alt özofagus sfinkterinde gevşeme kusuruyla seyreden, ilerleyici disfaji ve kilo kaybı ile seyreden bir hastalık olup, triple $A$ sendromunun önemli bir komponentidir (2). Akalazya tanısı için erken aşamada endoskopik ve özofagus baryum grafisi ile değerlendirme yetersiz kalabilir. Diğer motilite bozukluklarından ayırmak için en önemli yöntem şüphesiz manometridir (15). Bizim hastamızda baryum grafisindeki görünüm akalazya için tipik olmayıp ön planda kitle düşündürdü. Ancak üst GIS endoskopisi yapıldığında Z çizgisi üzerinde endoskopun geçişine izin veren bir darlık olduğu ve bu seviyenin üzerinde özofagusta genişleme olduğu saptandı. Teknik yetersizlikler nedeniyle manometrik inceleme yapılamadı. Hasta önceden kalsiyum kanal blokeri tedavisinden fayda görmesine rağmen, ilerleyen dönemde bu tedavi yetersiz kalmıştı ve hastaya buji dilatasyonu yapılmıştı. Buji dilatasyonundan da başlangıçta fayda görse de devamında disfajinin artması ve ağrılı hal alması üzerine hastaya dış merkezde Heller's myotomi yapıldı ve cerrahiden oldukça fayda gördü.

Alakrima her ne kadar triple A sendromlu olgularda ilk görülen belirti ve bulgulardan olsa da bizim olguda en son gelişen komponenti oldu (1,3). Alakrima olan çocuklar ağladıkları zaman çok az veya hiç göz yaşı üretemezler. Her ne kadar hastanın daha öncedeki yıllarda gözlerinde yanma ve batma gibi yakınmaları olsa da Schirmer's testi normal idi. En son yapılan kontrollerinde ise Schirmer's testi 5. dk da $5 \mathrm{~mm}$ in altında idi ve kuru göz kabul edildi. Hastaya sunni göz yaşı başlandı, ayrıca kuru göze bağı gelişen konjuktivit için deksametazon ve tobramisinli damla başlandı ve yakınmaları geriledi.

Triple A sendromlu olgularda gelişme geriliği, entelektüel yetersizlik, dizartri, mikrosefali, kas güçsüzlügü, hareket kusurları, periferik nöropati ve optik atrofi gibi nörolojik belirtiler bulunabilir ve zamanla daha da kötüleşebilir $(6,8,7)$. Bazı olgularda ise otonom disfonksiyona bağlı anizokori, anormal terleme, vücut ısı regülasyon bozukluğu ve kan basıncı değişiklikleri olabilir $(6,16,17)$. Bizim olgumuzda alt ekstremitlerde kas gücü $4 / 5$ idi ve dizartri mevcuttu. Hastanın daha önceki kliniğini de bildiğimiz için dizartisinde belirgin ilerleme mevcuttu. Ayrıca daha önceden olmayan vokal kord paralizisi de saptandı. MR da da mikroiskemik değişiklikler olduğu için asetil salisilik asit ve klopidogrel başlanması önerildi. Ancak gastriti olması nedeniyle aspirin başlanmadı ve klopidogrel tedavisi takip planlandı.

Sonuç olarak, triple A sendromunda akalazya ve alakrimayla ek olarak ACTH direncine bağlı adrenal yetersizlik gelişmekte ve hastalığın tüm komponentleri başlangıçta birarada ortaya çıkmayabilmektedir. Adrenal yetersizlik tedavisinde tek başına glukokortikoid yeterli olmakta, mineralokortikoid ihtiyacı genelde olmamaktadır. Bazı olgularda nörolojik bozukluklarda görülebilmektedir. Özellikle mineralokortikoid ihtiyacı olmayan adrenal yetersizliği olan olgular addisoniyanizm ve sendromun diğer spesifik iki bulgusu olan akalazya ve alakrima gelişimi yönünden takip edilmelidir.

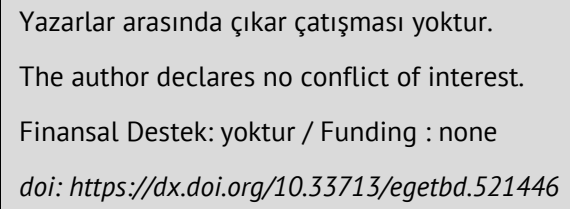

\section{KAYNAKLAR}

1. Roucher-Boulez F, Brac de la Perriere $A$, Jacquez $A$ et al. Triple-A syndrome: a wide spectrum of adrenal dysfunction. European journal of endocrinology / European Federation of Endocrine Societies 2018;178 (3):199-207. doi:10.1530/eje-170642

2. Hallal C, Kieling CO, Nunes DL et al. Diagnosis, misdiagnosis, and associated diseases of achalasia in children and adolescents: a twelve-year single center experience. Pediatric surgery international 2012;28 (12):1211-1217. doi:10.1007/s00383-012-3214-3 
3. Sarathi V, Shah NS Triple-A syndrome. Advances in experimental medicine and biology 2010;685:1-8

4. Atmaca $M S R$, Gönültaş $E$, Demir $M S$, Üçler $R$, Gönüllü $H$. Triple A Sendromu: Olgu Sunumu. Turk JEM 2014;18 (3):97-99

5. Appak YÇ ÇF, Şahin GE, Uluçay S, Huebner A, Kasırga E. Klinik ve genetik bulguları ile Triple A sendromu: Bir vaka takdimi. Çocuk Sağlığı ve Hastalıkları Dergisi 2014;57 (3): 195-199

6. Dumic M, Barisic N, Kusec V et al. Long-term clinical follow-up and molecular genetic findings in eight patients with triple $A$ syndrome. European journal of pediatrics 2012;171 (10):14531459. doi:10.1007/s00431-012-1745-1

7. Singh $K$, Puri RD, Bhai $P$ et al. Clinical heterogeneity and molecular profile of triple A syndrome: a study of seven cases. Journal of pediatric endocrinology \& metabolism : JPEM 2018;31 (7):799-807. doi:10.1515/jpem-2018-0023

8. Vishnu VY, Modi M, Prabhakar S, Bhansali A, Goyal MK "A" motor neuron disease. Journal of the neurological sciences 2014;336 (1-2):251-253. doi:10.1016/j.jns.2013.10.003

9. Prpic I, Huebner A, Persic M, Handschug K, Pavletic M Triple A syndrome: genotype-phenotype assessment. Clinical genetics 2003;63 (5):415-417

10. Handschug $K$, Sperling $S$, Yoon SJ, Hennig S, Clark AJ, Huebner A Triple A syndrome is caused by mutations in AAAS, a new WD-repeat protein gene. Human molecular genetics 2001;10 (3):283-290

11. Kind $B$, Koehler $K$, Lorenz $M$, Huebner $A$ The nuclear pore complex protein ALADIN is anchored via NDC1 but not via POM121 and GP210 in the nuclear envelope. Biochemical and biophysical research communications 2009;390 (2):205-210. doi:10.1016/j.bbrc.2009.09.080

12. Houlden $H$, Smith $S$, De Carvalho $M$ et al. Clinical and genetic characterization of families with triple A (Allgrove) syndrome. Brain : a journal of neurology 2002;125 (Pt 12):2681-2690

13. Bhargavan PV, Kumar KM, Rajendran VR, Fassaludeen AS Allgrove syndrome--a syndrome of primary adrenocortical insufficiency with achalasia of the cardia and deficient tear production. The Journal of the Association of Physicians of India 2003;51:726-728

14. Perry R, Kecha $O$, Paquette J, Huot $C$, Van Vliet G, Deal $C$ Primary adrenal insufficiency in children: twenty years' experience at the Sainte-Justine Hospital, Montreal. The Journal of clinical endocrinology and metabolism 2005;90 (6):32433250. doi:10.1210/jc.2004-0016

15. von Rahden BH, Filser J, Seyfried F, Veldhoen S, Reimer S, Germer CT [Diagnostics and therapy of achalasia]. Der Chirurg; Zeitschrift fur alle Gebiete der operativen Medizen 2014;85 (12):1055-1063. doi:10.1007/s00104-014-2803-1

16. Sanyal D, Bhattacharjee S A case of late-onset allgrove syndrome presenting with predominant autonomic dysfunction. Annals of Indian Academy of Neurology 2013;16 (2):266-268. doi:10.4103/0972-2327.112494

17. Singer W, Low PA Early Orthostatic Hypotension and Orthostatic Intolerance-More Than an Observation or
Annoyance. JAMA internal medicine 2017;177 (9):1324-1325. doi:10.1001/jamainternmed.2017.2923.. 